\title{
Organização eclesial e eficácia política O caso da Igreja Universal do Reino de Deus
}

\author{
Ari Pedro Oro
}

Este texto versa sobre a inserção da Igreja Universal do Reino de Deus (IURD) na política nacional. Meu argumento é que o seu sucesso eleitoral, que aumenta a cada nova eleição, deve-se fundamentalmente à sua forma de organização eclesial carismática e centralizadora e à sua capacidade de trazer para o campo político importantes elementos práticos e simbólicos do campo religioso. Em decorrência disso, como veremos, o possível carisma pessoal dos candidatos a cargos políticos egressos da Igreja fica subordinado ao carisma institucional da própria Igreja.

\footnotetext{
${ }^{1}$ Doutor em Antropologia, professor no Departamento de Antropologia da Universidade Federal do Rio Grande do Sul. Endereço: arioro@uol.com.br
}

Civitas, Porto Alegre, v. 3, № 1, jun. 2003 


\section{Carisma pessoal e carisma institucional}

Para Max Weber, carisma é uma qualidade extraordinária, de caráter extra-quotidiano, reconhecida como tal por um grupo social. O carisma caracteriza alguns indivíduos (profetas, feiticeiros, chefes militares, "demagogos") detentores de um carisma pessoal, mas também instituições do tipo igreja portadoras de um carisma de função, ou de instituição, derivado da apropriação de um carisma pessoal fundador (profético), rotinizado (Weber, 1971 , p. 249) ${ }^{2}$. A relação entre carisma pessoal e graça institucional, diz Bourdieu, é de luta pelo monopólio do exercício legítimo do poder religioso. Ou seja, a igreja, enquanto empresa burocrática de salvação ${ }^{3}$, "é incondicionalmente hostil ao carisma 'pessoal', isto é, profético, místico ou extático, que pretende indicar um caminho original em direção a Deus" (Bourdieu, 1987, p. 95). Ao mesmo tempo, a igreja preconiza que seus funcionários (padres ou pastores) "deve $(\mathrm{m})$ se subordinar à graça institucional sob pena de condenação..." (Séguy, 1982, p. 33); eles devem reproduzir as obrigações articuladas pela instituição proprietária do carisma de função (Ibid., p. 40).

O interesse teórico destas considerações é de duas ordens: em primeiro lugar, a IURD constitui uma organização em que ao mesmo tempo o seu fundador e a própria instituição são reconhecidos como portadores de carisma. Ou seja, é incontestável a autoridade carismática de Edir Macedo fundador da IURD -, reconhecida como tal tanto pelos membros da hierarquia quanto pelos fiéis, ao mesmo tempo em que é também forte o poder que emana da instituição Igreja Universal, adquirindo esta, entre seus fiéis, a condição de uma marca com forte densidade simbólica. No entanto, e em segundo lugar, relativamente à inserção da IURD no campo político, o carisma de função se mostra preeminente sobre o carisma pessoal dos candidatos a cargos eletivos indicados ou apoiados pela Igreja. Conseqüentemente, nesta instituição não se candidata a cargos eletivos quem quer, mas quem é escolhido pela cúpula dirigente da Igreja, e o reconhecimento

\footnotetext{
${ }^{2}$ Segundo J. Séguy, "para Weber o carisma de função representa uma derivação institucional do carisma pessoal quando este se rotiniza e assume, no processo, significações e funções novas. O carisma pessoal, por sua vez, caracteriza o profeta (no domínio religioso), ou o 'demagogo' (no domínio político), ou ainda o chefe de guerra de qualidades excepcionais (no campo militar)" (Séguy, 1988, p. 14-15).

${ }^{3}$ Para Bourdieu, "a Igreja apresenta inúmeras características de uma burocracia (delimitação explícita das áreas de competência e hierarquização regulamentada das funções, com a racionalização correlata das remunerações, das 'nomeações', das 'promoções' e das 'carreiras', codificação das regras que regem a atividade profissional e a vida extraprofissional, racionalização dos instrumentos de trabalho, como o dogma e a liturgia, e da formação profissional etc.)" (Bourdieu, 1987, p. 59-60).
} 
social que recebe, mediante a votação dos fiéis, dá-se mais por ser apoiado pela instituição religiosa do que por suas próprias qualidades pessoais.

\section{O sucesso político da Igreja Universal do Reino de Deus}

A IURD foi fundada no Rio de Janeiro em 1977 por Edir Macedo, um funcionário da loteria do Estado do Rio de Janeiro que até então tivera uma trajetória religiosa que o fizera passar do catolicismo para a umbanda e se converter ao protestantismo aos 18 anos de idade, na Igreja Nova Vida. Em 1975, fundou, com outros pastores, a Cruzada do Caminho Eterno e, dois anos mais tarde, com seu cunhado R. R. Soares, a Igreja Universal do Reino de Deus (Mariano, 2003).

Essa Igreja debutou na política em 1986 ao eleger um deputado federal para a Assembléia Nacional Constituinte. Este foi só o começo. Em 1990, elegeu 3 deputados federais e 6 deputados estaduais. Em 1994, duplicou o número de deputados para a Câmara Federal e elevou para 8 o número de deputados para as Assembléias Legislativas. Nas eleições de 1998, elegeu 26 deputados nas Assembléias Legislativas de 18 estados da federação (Fonseca, 1998, p. 20) e 17 deputados federais (sendo 14 egressos da própria Igreja de distintas unidades federativas e 3 deputados apoiados por ela).

Nas eleições 2000, a IURD elegeu dezenas de vereadores em todos os estados do país. Em 2002, aumentou ainda mais o número de deputados na Câmara Federal e nas Assembléias Legislativas dos estados. Segundo a Folha de S. Paulo, seriam "pelo menos 22 os parlamentares" eleitos de acordo com o deputado Bispo Rodrigues - principal coordenador político da IURD $^{4}$-, sendo 18 membros da igreja e 4 apoiados por ela nos Estados (Folha de S. Paulo, 10/10/2001). Além disso, fato notável foi a eleição do primeiro senador da Igreja, bispo Marcelo Crivella, pelo PL do Rio de Janeiro, com 3.235.570 votos, superando políticos tradicionais como Artur

\footnotetext{
${ }^{4}$ Bispo Rodrigues foi eleito em 1998 deputado federal pelo PFL do Rio de Janeiro com 76 mil votos. Reelegeu-se no último pleito com 192.640 votos, tendo obtido a quarta maior votação no conjunto dos candidatos à Câmara Federal do Rio de Janeiro. Bispo Rodrigues é hoje vice-líder do Partido Liberal (PL) na Câmara Federal. Este bispo fundou a Igreja Universal na Argentina e na Espanha e trabalhou em Portugal, Angola, África do Sul e Moçambique antes de se dedicar, em 1996, integralmente à tarefa de coordenador político da Igreja. Conrado atribui o sucesso eleitoral da IURD, entre outros fatores, à liderança deste bispo, que desde a campanha presidencial de 1989 coordena candidaturas e define estratégias políticas da IURD e, na Câmara Federal, conduz a ação política dos parlamentares nas questões que interessam à Igreja.
} 
da Távora e Leonel Brizola, além do pastor Manoel Ferreira, da Assembléia de Deus.

A crescente presença de representantes da IURD no Congresso Nacional contribuiu substancialmente para aumentar o tamanho da chamada "bancada evangélica". Na legislatura 1998-2002 somava 53 deputados ligados a 13 igrejas (Época, 2/10/2000) ${ }^{5}$. Tudo indica que essa bancada saiu fortalecida nas eleições de 2002. Segundo a Folha de S. Paulo, "a bancada evangélica de deputados federais eleitos tem pelo menos 60 parlamentares, donos de 5,1 milhões de votos", sendo 23 deputados filiados às Assembléias de Deus, 22 vinculados ou apoiados pela Universal, 8 batistas e os demais de outras denominações, o que significa um aumento de cerca de $25 \%$ em relação à bancada anterior (Folha de S. Paulo, 10/10/2002). Também no Senado aumentou o número de senadores evangélicos. Eram dois (Iris Rezende e Marina Silva), agora são quatro (Marina Silva, Bispo Crivella, Magno Malta e Paulo Otavio).

No entanto, há que se assinalar que a "bancada evangélica" não constitui um grupo político coeso. Segundo Fonseca, são raros os temas e as votações em que se pode perceber a existência de uma unidade evangélica. Ela só ocorre em assuntos ligados a temas que dizem respeito à moral. Por isso mesmo, continua Fonseca, "uma análise do comportamento do congressista evangélico mostra que esta "bancada" (evangélica) é um "mito" (Fonseca, 2002, no prelo). Conseqüentemente, salvo em casos esporádicos, no geral também não se pode falar em "voto evangélico", assim como há que se relativizar a existência de um "voto iurdiano" no Congresso Nacional (Ibid.).

\section{A eficácia política do carisma institucional}

Como procede a Igreja Universal para alcançar tal façanha no campo político? Ela resulta de um modo próprio de fazer política que adotara a partir de 1997 em nível nacional: o modelo corporativo da "candidatura oficial", cujo número de candidatos para os distintos cargos eletivos depende do capital eleitoral de que dispõe. Para sabê-lo, realiza, antes das eleições, uma espécie de "recenseamento" de seus membros/fiéis para descobrir seus dados eleitorais. Tais dados são apresentados aos bispos regionais, que por sua vez os transmitem ao Bispo Rodrigues. Juntos deliberam quantos candidatos devem lançar em cada município ou estado,

\footnotetext{
${ }^{5}$ Para uma análise da formação da Bancada Evangélica por ocasião da Constituinte de 1988 ver Pierucci e Prandi (1996). Para uma análise mais geral da bancada Evangélica na Câmara Federal, ver Freston (2000).
} 
dependendo do tipo de eleição, do quociente eleitoral dos partidos e do número de eleitores recenseados pelas igrejas locais. Lançados os cândidatos, usam os cultos, as concentrações massivas e a mídia própria (televisão, rádio, jornal) para fazer publicidade dos mesmos.

Além disso, no período que antecede as eleições é comum ao final dos principais cultos, sobretudo os dominicais, bispos e pastores divulgarem seus candidatos aos fiéis, muitas vezes levando-os ao "palco/altar", ou, quando ausentes, abrirem banners com fotos dos candidatos. Geralmente também afixam uma grande faixa no fundo dos templos onde se lê: "vamos orar pelos nossos representantes" (seguem os seus nomes), após o que aparece a passagem de Provérbios 29:2: "Quando se multiplicam os justos o povo se alegra; quando porém domina o perverso o povo geme". Em alguns domingos pré-eleitorais leva-se um banner representando uma urna eletrônica ao altar. Com ele o bispo ou o pastor que preside a reunião ensina de forma bastante didática os fiéis a votarem nos candidatos da IURD. Além disso, em Porto Alegre, por exemplo, no domingo dia 15 de setembro de 2002, uma urna eletrônica da Justiça Eleitoral estava à disposição dos fiéis no hall de entrada da catedral para os que quisessem treinar a votar.

A racionalidade política da Igreja vai além disso. Dependendo da eleição, ela distribui seus candidatos segundo bairros, cidades ou regiões, para serem apoiados separadamente pelos diferentes templos locais. Dessa forma, pode saber antecipadamente o número aproximado de votos de cada candidato.

Escolhido o(s) candidato(s), a "máquina" eclesial entra em funcionamento. Cumpre sublinhar que a escolha dos candidatos é prerrogativa exclusiva dos dirigentes regionais e nacionais da Igreja, segundo seus cálculos e interesses. Não há nenhuma consulta prévia aos membros das igrejas locais. Estes recebem, no momento oportuno, o(s) nome(s) em quem devem votar. Muitas vezes, trata-se de pessoas pouco conhecidas dos irmãos de fé. Isto, porém, não inviabiliza sua eleição.

Evidentemente que não é "qualquer um" que pode ser candidato. Ele deve ter o "germe do habitus" religioso e político, para usar a expressão de Jean Séguy, tal como é concebido pelos dirigentes da Igreja. A este propósito, Conrado efetuou levantamento na Folha Universal acerca do que a Igreja considera o perfil adequado do político: "pessoas despojadas de interesses pessoais"; "ter o desejo exclusivo de glorificar o bom nome do Nosso Senhor Jesus Cristo..."; possuir "caráter" e "compromisso com o póvo de Deus"; preocupar-se com os "desamparados, pobres e necessitados", "sem vaidades interiores, sem egoísmos..." (Conrado, 2000, p. 76-77). 
$\mathrm{Na}$ prática, como observou Freston, os principais pré-requisitos dos candidatos da Universal são os de serem "pastores que atuam na mídia" (Freston, 2000, p. 299). Ou seja, não seriam recém-chegados na Igreja e nem totalmente desconhecidos dos fiéis. No entanto, tais requisitos são insuficientes para garantir sua eleição. A votação que recebem resulta, em última instância, sobretudo do fato de terem sido escolhidos, indicados e/ou apoiados pelos dirigentes da Igreja enquanto "homens de Deus". O depoimento do deputado federal do PL do Rio Grande do Sul e pastor da Universal, Paulo Gouvea, sobre sua própria eleição em 1998 (e re-eleição em 2002) confirma isto: "A força da candidatura não está no meu nome. Se não fosse eu, seria outro e seria eleito da mesma forma; com absoluta certeza" (entrevista concedida em 8/10/2001). Da mesma forma, pastor Almerindo Filho, eleito vereador em Porto Alegre em 2000 pelo PFL, afirma sobre si mesmo e seu colega vereador, pastor Valdir Caetano, do PL: "a direção da Igreja nos escolheu (...). O apoio da Igreja é fundamental" (entrevista concedida em 29/6/2001).

Para comprovar, justamente, a força do carisma institucional, vale mencionar que, em Porto Alegre, na eleição de 2000, durante a campanha obrigatória no rádio e na televisão, a candidata à vereadora Veranice Neto compareceu todo o tempo na mídia dizendo-se "evangélica e membro da Igreja Universal do Reino de Deus", esperando desta forma, por certo, obter votos de seus irmãos de fé. No entanto, como se lançou candidata sem o apoio da Igreja, mesmo manifestando publicamente a sua condição de fiel da IURD, obteve apenas 186 votos. Seus irmãos não votaram nela, justamente por não ter sido nem indicada "oficialmente" e nem apoiada pela Igreja. Em contraste, Almerindo Filho, que fora indicado candidato oficial da denominação, elegeu-se.

O mesmo fato ocorreu nas eleições 2002. O candidato a deputado federal e os dois candidatos a deputado estadual indicados e apoiados pela Igreja receberam votação expressiva, elegendo-se com folga de votos, menos um deles por déficit de legenda ${ }^{6}$.

Outro elemento que comprova a força do carisma institucional iurdiano pôde ser observado nas últimas eleições. Com efeito, alguns parlamentares estaduais da Igreja, que nas eleições passadas foram apoiados por ela, tiveram este apoio retirado. Mesmo assim se lançaram como candidatos.

\footnotetext{
${ }^{6}$ Refiro-me ao pastor e deputado federal Paulo Gouvêa, do PL, que nas eleições de 1998 obtivera 70.983 votos e que nas eleições de 2002 reelegeu-se com 103.951 votos; ao pastor José Peres, candidato pelo PSB, eleito com 46.651 votos; e ao pastor Dalton Duarte, que concorreu pelo PL e que, embora tenha obtido a maior votação do partido, 40.093 votos, não se elegeu por falta de votos na legenda.
} 
Isto ocorreu, por exemplo, no Rio de Janeiro, no Ceará e no Rio Grande do $\mathrm{Sul}^{7}$. Em seu lugar, evidentemente, a Igreja apresentou e apoiou outros candidatos $^{8}$.

E o que ocorreu com os deputados que foram apoiados pela Universal nas eleições proporcionais passadas mas não na atual? Todos foram sumariamente derrotados.

É o caso do pastor Paulo Moreira que em 1998 concorreu a deputado estadual no Rio Grande do Sul e com o apoio da Igreja foi eleito com 60.474 votos. Nas eleições de 2002 , quando não contou mais com tal apoio, obteve apenas 2.464 votos $^{9}$.

Semelhante situação ocorreu com a candidata Magaly Machado, do Rio de Janeiro, que em 1998 foi eleita deputada estadual pelo PFL com 33.678 votos. Nas eleições de 2002 concorreu ao Congresso Nacional pelo PSB e contou com o apoio da Igreja Nova Vida, obtendo 9.418 votos. Já o pastor Mario Luiz elegeu-se deputado estadual pelo PFL em 1998 com 30.851 votos. Nas eleições de 2002 concorreu a deputado federal pelo PMDB como membro da Igreja Sara Nossa Terra, obtendo 11.489 votos.

No Ceará ocorreu fato semelhante. O pastor Heriberto, em 1998, apoiado pela "máquina" iurdiana foi eleito deputado estadual pelo PMDB com 43.904 votos. Em 2002 concorreu novamente a deputado estadual, pelo PL, mas sem o apoio da IURD: obteve apenas 1.338 votos.

Tudo o que precede mostra que Freston tem razão ao dizer que na Universal há uma relação de complementaridade entre carisma institucional e qualidades pessoais dos candidatos (Freston, 2000, p. 299). No entanto, argumento que o pólo institucional prepondera sobre o individual. Isto se deve à sua estrutura eclesial, que Carneiro denominou de "carismática, centralizada e não participativa" (Carneiro, 1998). Esta estrutura, segundo este autor, faz da IURD uma instituição na qual "o carisma apresenta-se como o único elemento de organização do poder, da igreja local à

\footnotetext{
${ }^{7}$ A Folha Universal, edição de 15-21 de setembro de 2002, divulgou nota esclarecendo que os deputados e candidatos à reeleição para a Assembléia Legislativa do Rio de Janeiro Mário Luiz e Magaly Machado, bem como o ex-pastor Eriberto da Silva Faria, também candidato a deputado estadual no Ceará, "não contam com o apoio dos membros da Igreja Universal do Reino de Deus". O mesmo ocorreu no Rio Grande do Sul com o pastor Paulo Moreira.

${ }^{8}$ Tudo indica que nesses casos a retirada do apoio se deveu ao fato de que tais deputados ou não se submeteram às diretrizes e orientações estabelecidas pelos articuladores políticos da Igreja ou não corresponderam às expectativas da Igreja.

${ }^{9}$ Cumpre observar que este candidato, que nas eleições de 1998 não expressava publicamente a sua condição religiosa, na última campanha, visando ampliar a sua viabilidade eleitoral, compareceu a programas de rádio e televisão dizendo-se "pastor evangélico".
} 
organização nacional, constituindo um espaço institucional pouco propício à participação dos fiéis nos assuntos da Igreja" (Carneiro, 1998, p. 187).

O Bispo Rodrigues sintetiza esta estrutura organizacional do seguinte modo: "Nossa força é que temos uma hierarquia, há uma hierarquia que é seguida à risca..." (Jornal do Brasil, 29/10/2001). O que implica dizer que o poder da instituição prevalece sobre o dos indivíduos, sejam eles simples fiéis ou pastores. Este poder chega a tal ponto que, segundo Conrado, o pastor eleito não é dono do seu próprio mandato. Ao contrário, "o político eleito pela IURD tem o seu mandato nas mãos dela, seguindo sua orientação nas questões de interesse da igreja. A legitimidade da sua representação deriva de um 'ato de instituição' que a organização faculta" (Conrado, 2000, p. 54-55). Exemplo disso seria a liberdade para votar segundo orientações partidárias ou segundo interesses da Igreja, bem como a permanência ou mudança de filiação partidária segundo um cálculo, também não desinteressado, realizado pela Igreja.

Obviamente, não dá para não perceber que por trás do carisma institucional há um reduzido mas poderoso grupo de indivíduos, liderado pelo Bispo Rodrigues, que exerce seu poder nos vários momentos da prática política iurdiana. Cabe a eles, de um lado, escolher os candidatos representantes da Igreja, segundo o tipo de eleição em questão, bem como distribuí-los entre os partidos políticos, e, de outro lado, orientar os bispos e pastores locais para solicitarem os votos dos fiéis.

Evidentemente que o exitoso exercício da autoridade carismática iurdiana na política não se dá de forma opressiva. A sua legitimação ocorre mediante a mobilização de vários elementos práticos e simbólicos. Ou seja, por um lado, a IURD faz uso da sua bem montada rede midiática, impressa, eletrônica e assistencialista. E, por outro lado, também traz para o campo político e para a construção da sua representação política, elementos doutrinários e discursivos presentes em sua cosmovisão religiosa, reproduzindo, assim, um procedimento comum aos evangélicos de "religiogizar" o político. Vamos nos ater brevemente sobre este segundo ponto.

Em primeiro lugar, a IURD tende a acionar no campo político o discurso milenarista, cuja intensidade guarda, até certo ponto, relação com as notícias veiculadas na imprensa nacional acerca da corrupção existente no próprio campo político. Ou seja, quanto mais a mídia divulga casos de escândalos de corrupção que ocorrem nas esferas públicas mais a Igreja apela e aciona o componente milenanista que se expressa, por exemplo, nesta frase do Bispo Rodrigues: faz-se necessário "uma grande reforma espiritual na vida do povo brasileiro" (Rodrigues, 1998, p. 27), da qual pode resultar uma nova moral pública e uma nova ética na política. Para tanto, continua o 
referido bispo, é "papel da Igreja do Senhor Jesus Cristo: anunciar a verdade, doa a quem doer e cobrar das nossas autoridades a prática dos princípios éticos e morais do nosso povo, de acordo com a própria Carta Constitucional do país" (Rodrigues, 1998, p. 29), além de conclamar o povo de Deus a eleger "homens e mulheres tementes ao Senhor Jesus" (subentende-se evangélicos) ${ }^{10}$.

Assim sendo, para a IURD - e para outras igrejas pentecostais ou reformadas - a corrupção constitui a antítese dos princípios cristãos de valorização da comunidade, do bem comum e da fraternidade, constituindose no inimigo do bem estar dos cidadãos, justificando e legitimando o seu ingresso na política uma vez que se consideram uma espécie de "reserva moral" da sociedade.

Vale a pena lembrar que este mesmo discurso pela ética na política é recorrente nas igrejas evangélicas em geral. No entanto, como escreveu Mariano, a experiência tem mostrado que em sua prática política, "vários parlamentares pentecostais, membros de igrejas e partidos conservadores, protagonizaram escândalos variados de malversação de recursos públicos e revêlaram possuir uma voracidade fisiológica que em nada diferia da dos piores de seus pares não crentes" (Mariano, 2001, p. 13-14).

Porém, quanto à atuação dos parlamentares iurdianos Conrado sublinha que eles não se envolveram em escândalos dessa ordem ${ }^{11}$. É esta também, e não há novidade nisso, a posição do Bispo Rodrigues: "em meio a tantas falcatruas e espertezas (que vigora na política do país) os homens e mulheres que levam o nome de Deus (subentende-se a bancada parlamentar da IURD) não se deixaram contaminar pela prática comum da corrupção. Os nossos candidatos mostraram, na prática, o que é verdadeiramente a ética na política" (Rodrigues, 1998, p. 7-8). Vai na mesma direção uma recente declaração do mesmo bispo, feita à Folha Universal, acerca dos seus compromissos enquanto parlamentar (e dirigente político da Universal):

\footnotetext{
${ }^{10}$ Eis, na íntegra, o pronunciamento de Bispo Rodrigues: "Conclamo o povo de Deus a que nos unamos em torno dos nossos ideais e não tenhamos medo de participar do processo político, elegendo homens e mulheres tementes ao Senhor Jesus a fim de que nossa sociedade seja transformada e possa ser orientada, segundo os verdadeiros princípios cristãos" (Folha Universal, 6/08/2000). O sociólogo e teólogo metodista Leonildo Campos lembra que o sonho de um novo começo social, de uma reconstrução sociopolítica, vigora no conjunto do protestantismo brasileiro e se expressa nesta quase palavra de ordem: "O Brasil será um país diferente quando à sua frente estiver um homem de Deus" (Campos, 2000, p. 21).

${ }^{11}$ Escreveu ele: "Não se teve notícias de que políticos ligados à Igreja Universal estivessem envolvidos nesses casos (de escândalos)" (Conrado, 2000, p. 60).
} 
Meu compromisso é manter a ética, cumprindo meu mandato em favor dos pobres e da nação. Quero combater a corrupção, lutar pela proteção do meio ambiente, pela reforma tributária, pela melhor distribuição de renda, partilha da terra, diminuindo a injustiça social. (Folha Universal, edição 550, 19/10/2002).

No entanto, e em segundo lugar, a construção de uma outra sociedade e de uma outra política subentende a vitória na guerra espiritual em que a Igreja está inserida. Ou seja, a IURD, mas não só ela, apela diretamente para o discurso das "forças invisíveis" atuando também na política (Corten e Mary, 2002) ${ }^{12}$. Em outras palavras, a simbólica da diabolização que, segundo Barros, constitui "... o eixo a partir do qual o universo simbólico desta igreja é construído" (Barros, 1995, p. 1), constitui também a chave pela qual a Universal conclama os seus fiéis a participarem da política, uma vez que ela vem a ser um importante reduto de atuação do satanás. "Os espíritos que atuam na política, disse recentemente o Bispo Rodrigues, são os espíritos dominadores, os príncipes das trevas" (Jornal do Brasil, 29/10/2001). Em outra oportunidade o mesmo bispo disse: "O diabo está alojado dentro do Congresso Nacional, criando lei injustas e erradas" (Folha Universal, n. 302, 18/01/1998). "A maioria dos políticos está a serviço do satanás", repetiam os pastores e bispos nos domingos que precederam a eleição de 6 de outubro de 2002.

Porém, se o diabo atua na política - ocasionando a corrupção, comportamentos antiéticos e oposição à "obra de Deus" - a Universal se diz capaz de libertá-la do poder do mal. Para tanto, aciona um poderoso recurso, a força que purifica tudo, inclusive a política: a "força do Espírito Santo", o "poder do Senhor Jesus", "o pai das luzes que vence o poder das trevas", segundo o dizer dos ministros da IURD.

A consequiência desse discurso é que para os fiéis iurdianos votar não constitui apenas um ato cívico e de cidadania. Ele é também concebido como um ato que preenche um sentido quase-religioso. Trata-se de um gesto de exorcismo do demônio que se encontra na política e de sua libertação para que ela seja ocupada por "pessoas tementes ao Senhor Jesus", segundo a expressão de Bispo Rodrigues. Não é por acaso que o slogan dos candidatos da IURD nas eleições de 1998 foi "fé para mudar", e que um dos lemas de campanha dizia: "conhecereis o seu voto e o seu voto vos libertará". Em outras palavras, o efeito de sentido produzido pelo discurso e pelo carisma da IURD no período que precede as eleições é tal que os seus fiéis acrescentam um significado a mais ao ato de votar além do dever cívico. O gesto de votar adquire o sentido de um rechaço do mal

${ }^{12}$ Para esses autores, o pentecostalismo dá continuidade a um processo de diabolização realizado pelos missionários, contribuindo, assim, para a globalização de um imaginário de forças do mal atuando na modernidade (Corten e Mary, 2000, p. 19). 
presente na política e sua substituição pelo bem, ou seja, por pessoas convertidas ao evangelho, por "verdadeiros cristãos", por "homens de Deus".

Portanto, a Universal mobiliza na esfera política crenças e valores do seu universo simbólico e a partir deles ressemantiza o voto, inscrevendo-o "numa lógica cosmológica, na perspectiva da guerra santa" (Semán, 2001, p. 96).

\section{Conclusão}

A título de conclusão gostaria de sublinhar três pontos.

Em primeiro lugar, não estou emitindo nenhum julgamento de valor acerca do modelo organizacional iurdiano e sua eficácia alcançada na política, até o presente momento. Percebo, no entanto, como mostro em outro lugar (Oro, 2003), que a prática política da Universal está produzindo um efeito mimético junto a outras igrejas evangélicas - tais como a Assembléia de Deus e a Igreja Quadrangular - que, em certa medida, perseguem semelhante sucesso obtido pela IURD procurando imitar, ao menos em parte, o seu modo de fazer política.

Em segundo lugar, o ingresso nos últimos anos da Igreja Universal e de outras denominações pentecostais no campo político constitui um fato novo, pois até a década de 60 o pentecostalismo brasileiro, e mesmo latinoamericano, assumia uma postura de distanciamento da política. Repetia-se, até então, que "crente não se mete em política". No entanto, hoje, como afirma Dodson - num estudo sobre o pentecostalismo na política e na esfera pública na América Latina -, a relevante participação pentecostal na sociedade civil (nas áreas do ensino, da saúde, e da assistência social), assim como a sua presença na política propriamente dita (apoiando candidatos leigos ou apresentando candidatos próprios), demonstra que o pentecostalismo desafia o estereótipo construído sobre ele enquanto passivo e indiferente em relação à sociedade e mesmo hostil em relação à política (Dodson, 1997, p. 34-36).

Enfim, fica em aberto a questão relativa ao efeito político do ingresso iurdiano (e pentecostal) na política. Em outras palavras, até que ponto estariam os representantes da Universal eleitos para os diferentes cargos políticos incidindo sobre o político, contribuindo para uma outra prática política, condizente com o seu discurso moralizador de ingresso na política? Por enquanto, como disse, o efeito da presença da IURD na política parece ser perceptível mais no campo religioso do que no campo político. Analisando a mesma questão, mas relativa não a uma denominação e sim ao 
pentecostalismo em geral, Corten sustenta que se, por um lado, o pentecostalismo pode ser considerado como instituinte da sociedade - por exemplo, através das identidades que suscita - por outro lado, em razão do seu ethos e de suas características próprias, não constitui uma fonte instituinte do político, não possui um papel de instituinte do político (Corten, 2001). Seja como for, somente o correr de mais um tempo poderá apontar respostas seguras a esta questão.

\section{Referências}

BARROS, Mônica do Nascimento. A batalha de Armagedom. Dissertação de Mestrado, UFMG, Belo Horizonte, 1995.

BOURDIEU, Pierre. A economia das trocas simbólicas. $2^{a}$ ed. São Paulo: Editora Perspectiva, 1987.

CAMPOS, Leonildo Silveira. Composições e recomposições do poder espiritual e político. In: Tempo e Presença, v. 22, n. 313, set.-out. 2000, p. 20-23.

CARNEIRO, Leandro Piquet. Cultura cívica e participação política entre evangélicos. In: FERNANDES, Rubem César et alii. Novo nascimento. Os evangélicos em casa, na Igreja e na política. Rio de Janeiro: Mauad, 1998, p. 81-210.

CONRADO, Flávio César dos Santos. Cidadãos do Reino de Deus (um estudo da "Folha Universal" nas eleições de 1998). Dissertação de Mestrado defendida junto ao Programa de Pós-Graduação em Sociologia e Antropologia da Universidade Federal do Rio de Janeiro, 2000.

CORTEN, Andre; MARY, Andre. Introduction. In: CORTEN, Andre; MARY, Andre. Imaginaires politiques et pentecôtismes, Afrique/Amérique Latine. Paris: Karthala, 2000, p. $11-33$

CORTEN, André. O pentecostalismo transnacionalizado no contexto teológico-político. In: Horizontes Antropológicos. n. 15, PPGAS/UFRGS, 2001, p. 149-160.

DODSON, Michael. Pentecostals, polítics, and public spacer in Latin America. In: Power, politics and pentecostals in Latin America. Boulder: Westview Press, 1997, p. 25-40.

FONSECA, Alexandre Brasil. Religion and democracy in Brazil (1998-2001): a study of the leading evangelical politicals. 2002 (No prelo).

FRESTON, Paul. The political evolution of Brazilian Pentecostalism: 1986-2000. In: CORTEN, Andre \& MARY, Andre (org). Imaginaires politiques et Pentecôtisme: Afrique et Amérique. Paris: Ed. Karthala, 2000, p. 287-306.

MARIANO, Ricardo. Islâmicos e evangélicos na arena pública. Veredas, Belo Horizonte, v. 1, $\mathrm{n}^{\circ}$ 1, ago. 2000, p. 49-64.

MARIANO, Ricardo. L'Église Universelle du Royaume de Dieu au Brésil. In: CORTEN, André, DOZON, Jean-Pierre, ORO, Ari Pedro. Paris: Karthala, 2003, (no prelo).

ORO, Ari Pedro. Pentecôtisme et politique au sud du Brésil. In: CORTEN, Andre et MARY, Andre (orgs). Imaginaires politiques et pentecôtismes, Afrique/Amérique Latine. Paris: Karthala, 2000, p. 307-320. 
ORO, Ari Pedro. L'Eglise Universelle: un pouvoir politique. In: CORTEN, André, DOZON, Jean-Pierre, ORO, Ari Pedro. Les nouveaux conquerants de la foi. Paris: Karthala, 2003, (no prelo).

PIERUCCI, Antonio Flavio e PRANDI, Reginaldo. A realidade social das religiões no Brasil. São Paulo: Hucitec, 1996.

RODRIGUES, Bispo Carlos. A Igreja e a política. Rio de Janeiro: Ed. Universal, 1998.

SÉGUY, Jean. Le clergé dans une perspective sociologique ou que faisons-nous de nos classiques? In: VI Colloque du C. S. P., Prêtres, pasteurs et rabbins dans la société contemporaine. Paris: Cerf, 1982, p. 11-58.

SÉGUY, Jean. Charisme de fonction et charisme personnel: le cas de Jean-Paul II. In: Voyage de Jean-Paul II en France. Paris: Cerf, 1998, p. 11-34.

SEMÁN, Pablo. A Igreja Universal do Reino de Deus: um ator e suas costuras da sociedade brasileira contemporânea. In: Debates do NER. N. 3, PPGAS/UFRGS, Porto Alegre, set. 2001, p. 87-96.

WEBER, Max. Economie et société. Paris: Plon, 1971.

Jornais e Revistas

JORNAL DO BRASIL, Rio de Janeiro, 29/10/2001.

ZERO HORA, RBS, Porto Alegre, 03/10/2000; 12/11/2000, .

FOLHA DE S. PAULO, 28/10/2000.

FOLHA UNIVERSAL, n. 396, 16/11/1999, 6/08/2000.

VEJA, edição de 3/11/1999.

ÉPOCA, n. 142, de 2/10/2000.

ECLÉSIA, São Paulo, n. 81, set./2002. 